\title{
Estágio Docente de Licenciatura de Computação: Um Ensaio do Ensino de Computação no Ensino Fundamental
}

\author{
José Andersson S. da Silva1, Hérikles Vinícyus F. Cordeiro ${ }^{1}$, Sônia R. Fortes da \\ Silva ${ }^{1}$, Anselmo L. Gomes ${ }^{1}$ \\ ${ }^{1}$ Universidade de Pernambuco, Campus Garanhuns (UPE) \\ CEP 55.294-902 - Garanhuns - PE - Brasil \\ \{anderssonsoares97, heriklescordeiro, fortes.sonia, anselmodsi \\ \} @gmail.com
}

\begin{abstract}
This article reports on the experience of undergraduates in Computing at the University of Pernambuco, Multicampi Garanhuns, during the course of Supervised Internship II, that was held at the School of Application Professora Ivonita Alves Guerra, at the Campus University of Pernambuco in Garanhuns. It describes the activities carried out in the classroom by these authors who acted as teachers, with the use of expository methodology, the classes consisted of theoretical explanations on topics related to computing, followed by practical activities. Allied to the use of the Construct 2 tool, we worked on the development of games, using the Problem Based Learning (PBL) methodology during the classes that constituted the Extension dimension. This experience verified the importance of the Supervised Internship for the teaching of Computing, thanks to the professional experience provided, regarding the learning developed by the students.

Resumo. Este artigo relata a experiência vivenciada pelos licenciandos em Computação da Universidade de Pernambuco - UPE, Multicampi Garanhuns, durante a disciplina de Estágio Supervisionado II, realizada na Escola de Aplicação Professora Ivonita Alves Guerra, no Campus da UPE em Garanhuns. Descreve as atividades realizadas em sala de aula por estes autores que atuaram como professores, com o uso de metodologia expositiva. As aulas consistiram em explicações teóricas sobre tópicos relacionados à computação, seguidas de atividades práticas. Aliados à utilização da ferramenta Construct 2, trabalhamos o desenvolvimento de jogos, utilizando a metodologia Problem Based Learning (PBL) durante as aulas que constituíram a dimensão Extensão. Esta experiência constatou a importância do Estágio Supervisionado para o ensino de Computação, graças a experiência profissional proporcionada, quanto à aprendizagem desenvolvida pelos estudantes.
\end{abstract}

\section{Introdução}

O ensino de Computação é indicado em todos os níveis da Educação Básica, da Educação infantil até o último ano do ensino médio, de acordo com a Computer Science Teacher Association (CSTA, 2005). Existe atualmente uma discussão no Brasil envolvendo a Sociedade Brasileira de Computação (SBC), e o Grupo de Trabalho de Ensino de Computação e Informática na Educação Básica (GT3), para a implementação do componente curricular da Computação na Base Nacional Comum Curricular ${ }^{1}$ (BNCC) 
área de conhecimento que ajuda a construção do Pensamento Computacional em estudantes e a inserção do jovem no Ecossistema e na Cultura Digital. Para tal competência e habilidade na construção desses eixos pelos educandos, existe no Brasil o Curso de Licenciatura em Computação para fomentar e contribuir para a consolidação do que seria Educação e Computação, bem como, o seu papel para a formação de uma sociedade 4.0, será exigido dos profissionais o desenvolvimento de uma visão multidisciplinar (Freitas, 2016).

Considera-se que a introdução de Computação, enquanto ciência, na Educação Básica é de fundamental importância e relevância (CSTA, 2011) para o desenvolvimento do cidadão da sociedade contemporânea. A sua inexistência limita a capacidade dos educandos de lidar com os avanços da sociedade cada vez mais globalizada e tecnológica, privando os educandos de múltiplos caminhos profissionais futuros, que orientam inovação, autonomia, competência e habilidades tecnológicas para programar e criar artefatos que auxiliem o ser humano em educação, saúde e outros setores de produção. A inexistência para um grupo e a existência para outro grupo de educandos desta formação cria um fosso entre a exclusão e inclusão dos formandos para o seu exercício profissional. Aqueles que tiveram contato com o ensino de computação no ensino fundamental terão facilidade no curso técnico estadual e federal, sendo um diferencial para o êxito na última etapa da Educação Básica, na educação superior e na vida social e profissional.

Porém, no Brasil, esta área de conhecimento não faz parte da BNCC conforme a proposta da $\mathrm{SBC}$, pelo desconhecimento dos educadores sobre esta área, pela quantidade de propostas existentes na BNCC para o currículo escolar e pela Lei Fiscal que impossibilita Estado e Município de aumentarem seus custos com os professores, impossibilitando contratações de profisssionais de Licenciatura em Computação. A sociedade solicita a existência de cursos de Licenciatura em Computação na graduação, mas o Estado não materializa o seu exercício, excluindo a sociedade brasileira deste ensino na Educação Básica. Expropria-se o estudante deste conhecimento, excluindo-o da evolução tecnológica e do êxito profissional, aumentando a força de trabalho desqualificada e barata.

A partir destas visões, muitas vezes antagônicas, o Estágio Supervisionado dos cursos de Licenciatura em Computação é considerado um dos principais articuladores de formação profissional do ensino de Computação no ensino fundamental e médio. Em diversas vezes, o Estágio Supervisionado proporciona aos educandos das escolas públicas, o contato inicial com o ensino de Computação, ministrado por professores da área de Educação, e de Computação, sendo muitas vezes sua proposta interdisciplinar ou com base no Referencial de Ensino de Computação na Educação Básica (SBC, 2017).

Com isto, a partir da experiência docente orientada, estudantes da Licenciatura em Computação lançam mão dos seus conhecimentos, para exercer a profissão e averiguar os problemas deste exercício, resultando em futuros docentes mais autônomos, que estruturam soluções de situações-problema, construindo conteúdos educacionais e artefatos de auxílio para tratar temas atuais, apresentando inovações na forma de aprender e de compreender os fenômenos dos saberes escolares.

Nesse contexto, o presente artigo relata a experiência de um grupo de discentes do Curso de Licenciatura em Computação da Universidade de Pernambuco, Multicampi Garanhuns, que através do projeto de Estágio Supervisionado, atuaram como docentes na Escola de Aplicação Professora Ivonita Alves Guerra, no Campus da Universidade de Pernambuco. As atividades do Estágio Supervisionado foram subdivididas por meio das 
atividades de Ensino e Extensão, cada uma contendo um objetivo específico a ser alcançado, integradas nas atividades da docência.

\section{Estágio em Licenciatura em Computação}

De acordo com Kulcsar (2012), os estágios supervisionados são considerados uma parte importante da relação trabalho-escola e da teoria-prática, por propiciar ao docente em formação uma visão da realidade a qual será submetido após sua graduação, possibilitando com os conhecimentos aprendidos na graduação e na vida escolar, exercer a profissão em sala de aula, o que, até então, fora transmitido no decorrer do curso somente no aspecto teórico (PIMENTA, 2001).

De acordo com a Lei $\mathrm{N}^{\circ} 11.788$, de setembro de 2008, conceitua-se estágio, sendo $\mathrm{o}$ ato educativo escolar supervisionado, desenvolvido no ambiente de trabalho, que visa à preparação para o trabalho produtivo de educandos que estejam frequentando o ensino regular em instituições de educação superior, de educação profissional, de ensino médio, da educação especial e dos anos finais do ensino fundamental, na modalidade profissional da educação de jovens e adultos. (BRASIL, 2008, Parágrafo $1^{\circ}$ ).

Este expõe o objetivo de proporcionar ao aluno o exercício de suas habilidades, aplicando seus conhecimentos acadêmicos em situações práticas, adquirindo uma experiência que sirva de base para a construção de uma visão crítica do exercício de suas habilidades como destaca Oliveira e Cunha (2006). Espera-se que, com isso, o aluno tenha a opção de incorporar atitudes práticas e adquirir uma visão crítica de sua área de atuação profissional.

Neste âmbito, percebe-se a importância na formação do licenciando em Computação, ao inseri-lo na posição de professor de Computação no ensino fundamental, tendo em vista as discussões pelo qual passa o país, com propostas de implementações do ensino de conceitos básicos nas escolas, que tende a seguir alguns países que têm implantado um currículo mínimo de Computação em suas escolas (CSTA, 2005).

Porém, no Brasil, esses debates sobre a implantação de um currículo de Computação na Educação Básica ainda não tiveram avanços significativos desde seu início. Devido a isso, este artigo relata a execução do projeto da disciplina de Estágio Supervisionado, que viabilizou de forma experimental a implantação da disciplina no ensino fundamental do $6^{\circ}$ ao $8^{\circ}$ ano, visando a importância de projetos como esse, que geram resultados importantes para discussões sobre a implementação na BNCC.

\section{Computação e Educação}

Com o advento da computação seu impacto na sociedade proporcionou transformações sociais, mesmo com apenas 100 anos de existência como ciência. A Computação tem como ponto principal a ferramenta do raciocínio lógico para o tratamento de situaçõesproblemas, está que não se restringe apenas no âmbito computacional. Tendo conhecimento dos benefícios proporcionado por essa ciência, vários pesquisadores estão direcionando e publicando seus trabalhos a fim relatar as experiências e corroborar com a importância da inclusão da computação na Educação Básica.

Segundo França (2014) a sala de aula não condiz com a necessidade que a sociedade moderna exige de seus cidadãos. A educação brasileira contém indícios de que mantém o padrão de 50 anos atrás: Carteiras enfileiradas, quadro branco, livros, e o professor atuando como centro das aulas, e como única fonte de conhecimento. Tal 
metodologia não ajuda o aluno a construir a capacidade de aprender por si próprio, buscando soluções para suas dúvidas e dificuldades.

França e Amaral (2013) ao realizarem um mapeamento sistemático dos trabalhos apresentado no Simpósio Brasileiro de Informática na Educação (SBIE), o Workshop de Informática na Escola (WIE) e o Workshop sobre Educação em Computação (WEI), demonstraram que o interesse no tema "Ensino de Computação na Educação Básica" está em ascensão - mesmo sendo bastante recente se comparado ao ensino de outras ciências como Matemática, Biologia, Física, entre outras.

\section{Método e Operacionalização}

O método foi qualitativo e de pesquisa exploratória, quando se estuda e aplica referenciais de ensino de Computação entre escola e profissionais de Licenciatura em Computação, acompanhando e analisando cada passo em sala de aula. Realizou-se um plano de trabalho para a orientação dos envolvidos nas atividades do Projeto na Escola de Aplicação Ivonita Alves Guerra.

Os estagiários, juntos aos professores orientadores, construíram um programa de componente curricular para cada turma do sexto ao oitavo ano, compondo a disciplina de Computação Educacional, após discussões sobre as regras da escola o programa foi elaborado com intuito de desenvolver o pensamento computacional dos educandos, contextualizando com a sociedade no qual está inserido, abrangendo três pilares: Pensamento Computacional (PC), Ecossistema Digital (ED) e Cultura Digital (CD).

Em seguida, a construção do programa iniciou um processo de estudo dos conteúdos, preparação de planos de aula, material de estudo para os educandos, atividades, avaliações, com cada passo acompanhado pelos professores no campo de estudo da escola de aplicação.

$\mathrm{Na}$ dimensão Ensino realizou-se atividades sobre: Introdução a Computação, Pensamento Computacional, História da Computação, Sistemas Operacionais, A evolução da Cultura Digital na humanidade, Representação de Algoritmos usando pseudocódigo, Introdução ao HyperText Markup Language 5 (HTML5), Introdução ao Cascading Style Sheets (CSS 3) e Continuação ao HTML5, Princípios de Programação ao decorrer de nove aulas, abordando os assuntos descritos, das quais, seis trataram do Pensamento Computacional, por meio de assuntos relacionados, sendo as três primeiras deste pilar, trabalhadas com atividades desplugadas. Estas aulas com intuito de criar uma familiarização dos estudantes com a história e importância do uso do computador para a atual sociedade.

Como exemplo, a atividade desplugada "Cidade Enlameada", do livro Computer Science Unplugged, que mostra como os computadores são usados para encontrar as melhores soluções para os problemas da vida real, tais como conectar linhas elétricas entre casas, encontrando menor caminho que ligasse todos os pontos. 


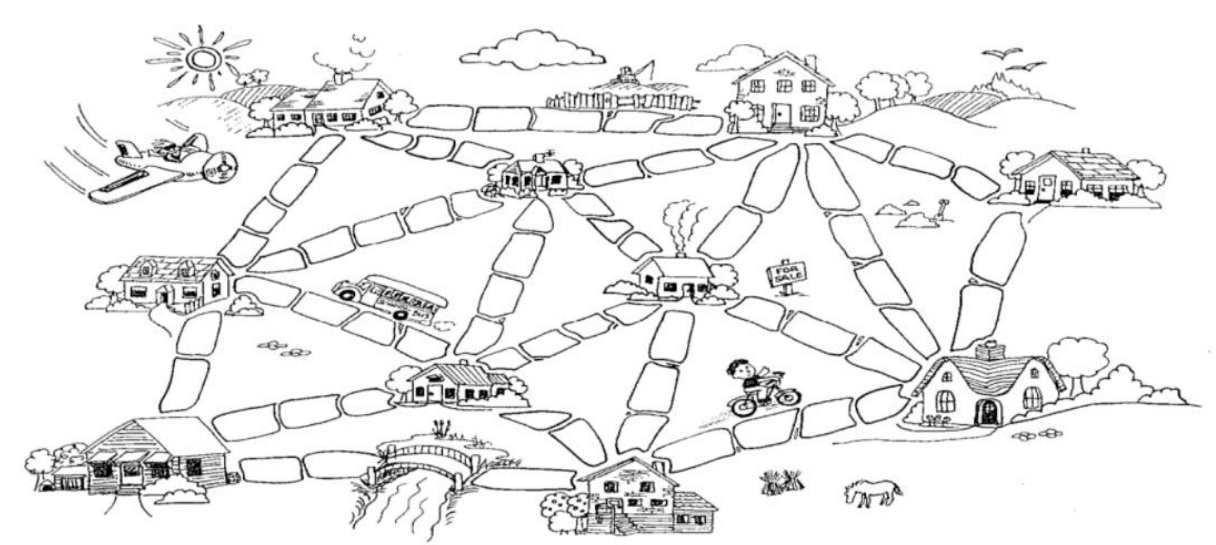

Figura 1. Planilha de Atividade: $O$ problema da Cidade Enlameada. Fonte: Computer Science Unplugged (1995)

As três demais aulas ocorreram no laboratório, onde as atividades desenvolvidas em conjunto ao computador, consistiram em conceitos de programação web.

Para a dimensão Extensão projetamos o desenvolvimento de um jogo com elementos básicos para que de maneira lúdica fosse ensinados os conceitos de lógica de programação, ao longo do projeto, onde o auxílio dos estagiários poderia ser solicitado, quando necessário para sanar dúvidas. Optamos por usar a ferramenta Construct 2, um programa que criar jogos de computador utilizando HTML5, de forma offline, possuindo uma versão gratuita. A atividade ocorreu em três aulas, dedicadas ao desenvolvimento dos jogos, sendo estas, divididas em quatro momentos, que podem ser observados na Figura 2.

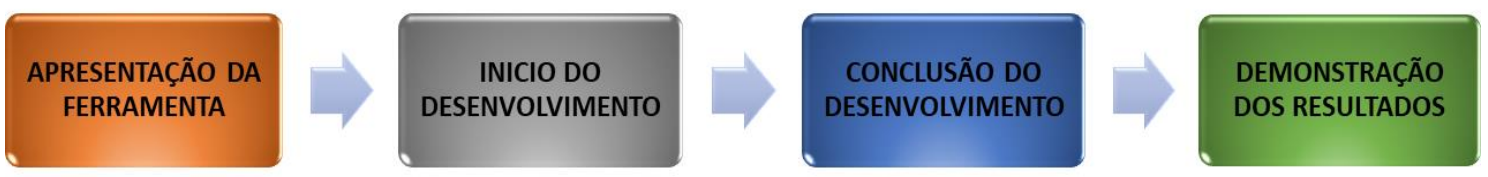

Figura 2. Fluxograma apresentando as etapas da Extensão.

A imagem da Figura 2 demonstra as etapas da dimensão Extensão, tais etapas ocorreram nas três aulas previstas, sendo a terceira aula, utilizada para realizar as duas últimas etapas, Conclusão do Desenvolvimento do Projeto e Demonstração dos Resultados, respectivamente.

A Demonstração dos Resultados ocorreu de forma expositiva dialógica, onde os alunos puderam apresentar seus jogos para os demais colegas, discutindo sobre as ideias que basearam a criação.

Estes jogos criados, eram compostos por apenas uma fase, devido ao curto espaço de tempo que tínhamos disponível. Visando a criação do projeto, de forma atrativa, optamos por usar a metodologia Problem-Based Learning (PBL) durante as aulas da Extensão, tratando os alunos como sujeitos ativos, da seguinte maneira: após apresentação da ferramenta a ser utilizada e os conceitos iniciais de utilização, era proposto uma atividade relacionada ao jogo, a qual, ao ser realizada, contribuiria para a construção do projeto, os mesmos contavam com acesso à internet para realizar buscas por soluções, e podiam solicitar ajuda aos estagiários para solucionar dúvidas.

\section{Resultados da experiência no ensino de Computação}


O propósito do Estágio Supervisionado II foi criar um ambiente de ensino de Computação no ensino fundamental, o mais real possível, contribuindo para a formação de educandos e estagiários de Licenciatura em Computação, em decorrência da inexistência do ensino de Computação na Educação Básica do município de Garanhuns. Objetivou-se implementar uma vivência da computação no ensino fundamental, conforme as discussões anteriormente citadas.

Os tópicos a seguir descrevem as etapas que foram realizadas nessa experiência tão significativa nos âmbitos de Ensino e Extensão, desde o planejamento, preparação do material, até a finalização da execução e os resultados obtidos com este trabalho.

\subsection{Ensino}

Os estagiários receberam a informação que não teriam a supervisão e colaboração de um professor de Computação nas atividades em sala de aula, pois a instituição não possuía tais profissionais. Todavia os professores supervisores da disciplina de Estágio II, que acompanharam e contribuíram na construção do planejamento. Assim, nesta primeira etapa realizamos algumas reuniões técnicas e psicopedagógicas sobre as aplicações das atividades de estágio supervisionado. Após esta etapa, iniciamos a dimensão de Ensino

Através de reuniões realizadas antes do início da dimensão de Ensino, este grupo ficou responsável por ministrar aulas nas turmas do $7^{\circ}$ (sétimo) ano do ensino fundamental. Ciente dessa informação e partindo da diagnose de que os educandos não tinham base de conhecimento sobre Computação e a abordagem dos eixos do Referencial, foi proposto um plano de trabalho entre a realidade e o proposto pela SBC para o ensino de Computação.

A escola não ofertava a disciplina Computação ou componente curricular semelhante, que construísse uma base sobre o assunto, sendo organizada uma sequência de aulas e atividades para inicialmente fazer com que os aprendentes descobrissem o que é a computação, assim incentivando a curiosidade na área, e subsequentemente os mesmos tivessem base para que o programa de atividade previsto fosse concluído.

No momento inicial do primeiro encontro realizou-se uma sondagem nos discentes para observar seus conhecimentos em Computação a fim de construir uma base necessária e confluir as aulas seguintes. Na segunda e terceira aulas contou com uma explanação do que é Computação e uma introdução ao PC e atividades como as do livro Computer Science Unplugged (1995) para melhor compreensão, nas três aulas seguintes, os planos de aula davam-enfoque em explanar a CD e ED. 


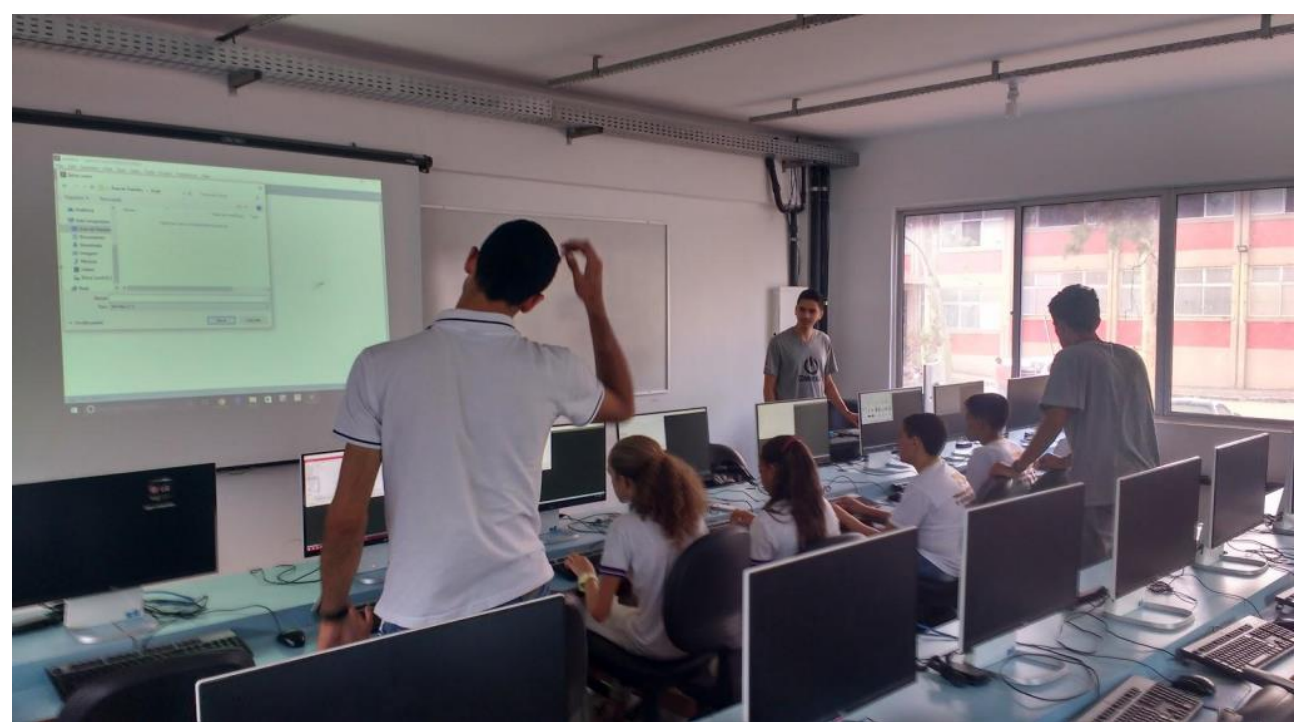

Figura 3. Aula exploratória sobre Computação e Pensamento Computacional.

Enquanto CD abordou o que era um computador, a evolução dos computadores ao longo do tempo e os impactos dessa evolução na sociedade, como um todo. Quando o grupo pensou na execução dessa aula o foco era identificar o uso de tecnologia nas diferentes dimensões da vida escolar, social e profissional e riscos acarretados por vírus, tudo isso através de linhas do tempo da CD. A aula com foco no ED foi montada para que os educandos compreenderem as diferenças e a relação entre o software e hardware, logo, nessa aula o assunto explanado: Sistema operacional (S.O), camadas de S.O e o que é Hardware e Software.

É possível dividir a dimensão Ensino em 5 fases para a melhor compreensão do que foi realizado:

Tabela 1: Fases executadas na Dimensão Ensino.

\begin{tabular}{|l|l|}
\hline Fase 1 & Planejamento e organização dos assuntos para o ano escolar referente \\
\hline Fase 2 & $\begin{array}{l}\text { Primeira aula: Sondagem do conhecimento que os alunos já tinham sobre os } \\
\text { assuntos, explanação sobre esses conhecimentos, breve revisão. }\end{array}$ \\
\hline Fase 3 & $\begin{array}{l}\text { Segunda e terceira aulas: Introdução ao PC e realização e explicação da } \\
\text { atividade "O problema da Cidade Enlameada", respectivamente. }\end{array}$ \\
\hline Fase 4 & $\begin{array}{l}\text { Quarta e quinta aulas: Introdução a CD, riscos e impactos de CD para a } \\
\text { sociedade. }\end{array}$ \\
\hline Fase 5 & $\begin{array}{l}\text { Sexta aula: Introdução a ED e inicialização do assunto de Hardware e } \\
\text { Software }\end{array}$ \\
\hline
\end{tabular}

\subsection{Extensão}

O eixo de Extensão teve início logo após as análises das atividades avaliativas realizadas no eixo de Ensino. Baseado nos resultados obtidos nos exercícios avaliativos e na observação que os estagiários viveram nas aulas anteriormente ministradas - os discentes demonstraram grande entusiasmo quando explanado como era construído um softwarefoi planejado um minicurso de desenvolvimento de conceitos iniciais e desenvolvimento 
de jogos usando a ferramenta Construct 2, editor de jogos 2D baseado em HTML5. A escolha dessa ferramenta ao invés de uma linguagem de programação de alto nível como JavaScript ou frameworks, como o Allegro-biblioteca para jogos 2D feita em C, dá-se ao fato que estes itens citados rogam pela necessidade de explicações sobre conceitos que influenciariam a aprendizagem dos discentes, devido ao curto espaço de tempo disponível, tal prática se tornaria inviável.

Após um levantamento feito, o minicurso ocorreu no período de três encontros com a carga horária de duas horas cada, assim atendendo as necessidades dos alunos. $\mathrm{Na}$ primeira aula tratamos sobre os conceitos básico de planejamento e construção de jogos, desde os sprites, sheet até o que são motores gráficos. Já introduzido a ferramenta de criação e edição de jogos a ser utilizada no decorrer do minicurso o Construct 2.

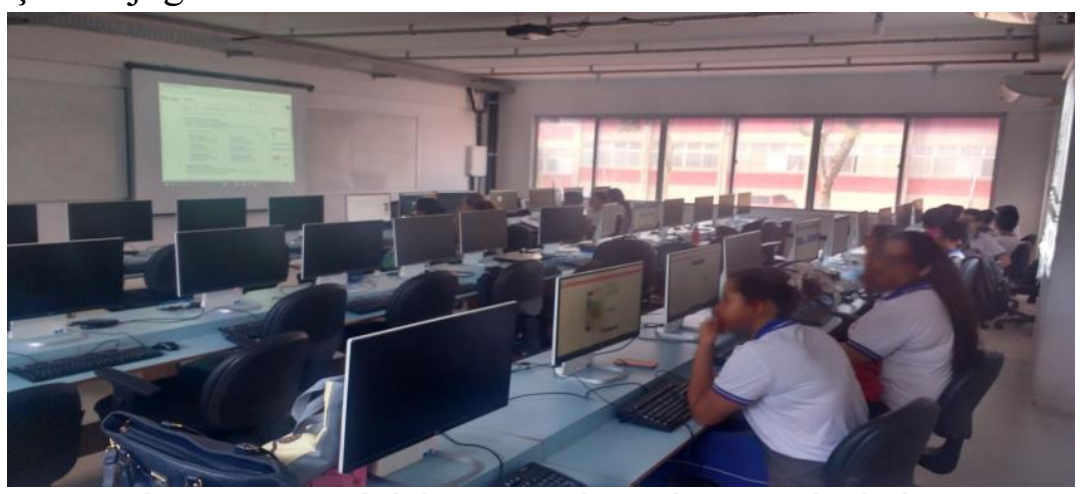

Figura 4. Aula inicial do Projeto Final da disciplina.

Na segunda aula os estagiários continuaram a apresentação da ferramenta usando uma abordagem prática. Ao decorrer de toda aula os discentes, com auxílio e supervisão dos estagiários, participaram da criação de um jogo de plataforma que abordou conceitos como: jogabilidade de plataforma, inserção de personagem, movimentação $2 \mathrm{D}$, troca de fases e inserção de música. Toda a base inicial para a criação dessa categoria. A última aula foi dedicada para os participantes criassem seus próprios jogos usando o aprendizado da aula anterior e informações contidas na documentação do Construct 2, sendo este jogo a avaliação final do minicurso.

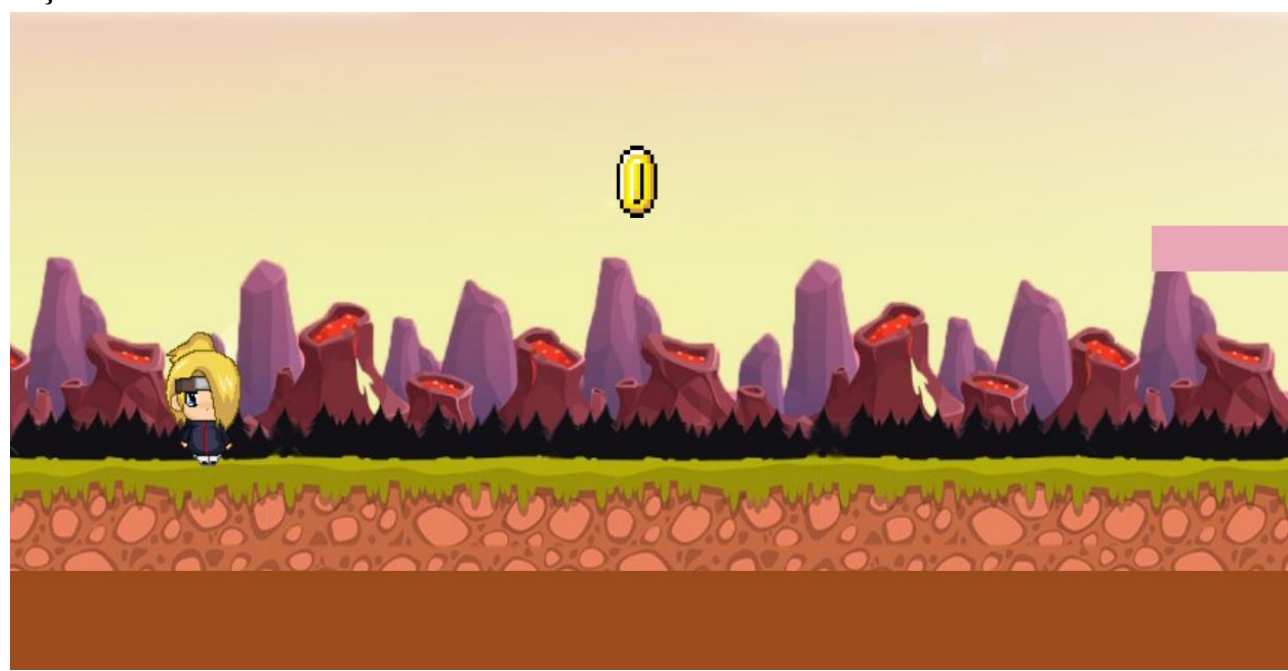

Figura 5. Projeto finalizado por um dos grupos de alunos. 
A Figura 5 apresenta o resultado dos projetos de uma das equipes. Nela, é possível observar que mesmo em um curto espaço de tempo e dispondo de pouca experiência com esta ferramenta, os resultados obtidos foram surpreendentes, estes possibilitados pelo uso da ferramenta, junto ao site Game Art 2 $\mathrm{D}^{1}$ que possibilita o download de sprites gratuitos.

\section{Considerações finais}

A sociedade contemporânea demonstra uma demanda crescente pelo domínio dos conceitos de Computação, sejam eles no âmbito escolar ou no meio profissional, para suprir as mais variadas necessidades, derivadas de uma sociedade cada vez mais conectada e interativa que preza pela produtividade e domínio da capacidade de adaptação às novas tendências tecnológicas nos meios de produção.

É papel da escola fornecer a devida formação aos estudantes que fazem parte desta sociedade, que junto ao Licenciado em Computação, devem compor um sistema de ensino capaz de oferecer condições para que estes estudantes desenvolvessem as capacidades necessárias nos pilares que compõem à Computação Educacional.

Diante o que ocorreu no estágio, podem ser elencados pontos relevantes para esse relato, os resultados obtidos tanto no Ensino quanto na Extensão foram gratificantes, pois mesmo com a dificuldade dos alunos, por não possuir o arcabouço de conhecimento necessário para o que foi estabelecido naquele nível escolar trabalhado, os mesmo, conseguiram realizar as atividades previstas, sem estagnar em determinado ponto do cronograma, mostrando que o aprendizado ocorreu de forma intuitiva ao decorrer das aulas, e das pesquisas realizadas, estimulando-os a construção das capacidades de raciocínio, pesquisa, e solução de problemas.

Considerando que no Brasil o ensino de Computação não faz parte da BNCC e que as discussões avancem lentamente, concluímos que trabalhos como este, que relatam os excelentes resultados que projetos experimentais exercem, proporcionando aos alunos envolvidos o desenvolvimento do pensamento computacional e conceitos diretamente e indiretamente relacionados, são de profunda importância para o desenvolvimento de discussões que propiciem a implementação deste componente curricular na BNCC.

\section{Referências}

Allegro. Disponível em: $<$ http://desenvolvimentodejogos.wikidot.com/allegro $>$. Acesso em 12 de maio de 2018.

Bell T.C.G., Witten, I. (1995).“Computer Science Unplugged: Capturing the interest of the uninterested". Anais do NZ Computer Conference,Wellington, Nova Zelândia.

BRASIL. Constituição (1988). Constituição da República Federativa do Brasil. Brasília, DF: $\quad$ Senado $\quad$ Federal, $1988 . \quad$ Disponível em: $<$ http://www.planalto.gov.br/ccivil_03/_ato2007-2010/2008/lei/111788.html > Acesso em: $09 / 12 / 2017$.

Construct 2 Disponível em: <https://www.scirra.com/>. Acesso em 10 de dezembro de 2017.

CSTA - Computer Science Teacher Association. (2005) "The New Educational Imperative: Improving High School Computer Science Education”. Final Report

\footnotetext{
${ }^{1}$ www.gameart2d.com
} 
of the CSTA. Curriculum Improvement Task Force. ACM - Association for Computing Machinery.

CSTA - Computer Science Teacher Association. (2011) "CSTA K-12 Computer

Science Standards”. CSTA Standards Task Force. ACM - Association for Computing Machinery.

Freitas (2016). “Alunos e Escolas para a Sociedade 4.0”. Revista Linha Direta, 15 de Julho.

França R.S., Ferreira V.A.F., Almeida L.C.F., Amaral H.J.C. (2014). “A disseminação do pensamento computacional na educação básica: lições aprendidas com experiências de licenciandos em computação" XXXIV Congresso da Sociedade Brasileira de Computação - CSBC.

França R.S. Amaral H.J.C. (2013). "Ensino de Computação na Educação Básica no Brasil: Um Mapeamento Sistemático" Disponível em: $<$ http://www.lbd.dcc.ufmg.br/colecoes/wei/2013/009.pdf $>$. Acesso em 21 março 2017.

JavaScript. Distonivel em : < http://tableless.github.io/iniciantes/manual/js/ $>$. Acesso em 12 de maio de 2018.

Kulcsar, Rosa (2012). O estágio supervisionado como atividade integradora. In: Fazenda, Ivani Catarina Arantes [etall]; Piconez, Stela C. Bertholo (Coord.). A prática de ensino e o estágio supervisionado. Campinas-SP: Papirus.

Nunes, D. J. (2011). “Ciência da Computação na Educação Básica”. Jornal da Ciência, 09 de Setembro.

Oliveira, E.S.G.; CUNHA, V.L. O estágio Supervisionado na formação continuada docente à distância: desafios a vencer e Construção de novas subjetividades. 2006. In: BERNARDY, Katieli1; PAZ, Dirce Maria Teixeira. Importância do estágio supervisionado para a formação de professores. 2012. Disponível em: Acesso em 09/12/2017.

Pimenta, S. G. O estágio na formação de professores: unidade teórica e prática? 4. ed. São Paulo: Cortez, 2001. 